\title{
Sazan Balığı (Cyprinus carpio, L., 1758)'nın Yaş Tayininde 6 Farklı Kalsifiye Yapının Değerlendirilmesi
}

\author{
Zafer ARSLAN ${ }^{1}$, Ramazan YAZICI ${ }^{2 *}$
}

\section{Öz}

Bu araştırmada Çoğun Baraj Gölü’nde yaşayan Cyprinus carpio’nun en güvenilir kalsifiye yapısı belirlenmiştir. Yaş tayini amacı ile pul, omur, asteriskus, lapillus, operkül ve suboperküller alınmıştır. Güvenilir kalsifiye oluşumu tespit etmek amacı ile yüzde uyum (YU), ortalama yüzde hata (OYH) ve değişim katsayısı (DK) hesabı yapılmıştır. Tekrarlı okumalar neticesinde tüm yapılarda 4 yıl sınıfı elde edilmiş olup en baskın yaş grubunun 5 yaş olduğu belirlenmiştir. Analiz sonuçlarına göre en yüksek yüzde uyum asteriskusta (\%76.8) tespit edilirken en düşük yüzde uyum ise suboperkülde (\%31.0) saptanmıştır. OYH ve DK değerleri en düşük asteriskusta $(\mathrm{OYH}=2.79, \mathrm{DK}=3.94)$ tespit edilmiştir. Sonuç olarak türün yaş tayini için güvenilir kalsifiye yapı asteriskus olarak belirlenmiştir.

Anahtar Kelimeler: Sazan balığı, Yaş tayini, Cyprinus carpio, Çoğun Baraj Gölü.

\section{Evaluation of 6 Different Calcified Structure in Age Determination of Common Carp (Cyprinus carpio, L., 1758)}

\begin{abstract}
In this study, the most reliable calcified structure of Cyprinus carpio living in Çoğun Dam Lake was determined. Scales, vertebra, asteriscus, lapillus, operculum and subopercules were taken for age determination. Percentage of agreement (PA), average percentage of error (APE) and coefficient of variation (CV) were calculated in order to determine reliable calcified formation. As a result of repeated readings, 4-year class was obtained for all calcified structures and it was determined that the most dominant age group was 5 years. According to the results of the analysis, the highest PA was detected in the asteriscus (76.8\%), while the lowest PA was found in the subopercule (31.0\%). The lowest APE and CV values were determined in asteriscus ( $\mathrm{APE}=2.79, \mathrm{CV}=3.94)$. As a result, the reliable calcified structure for age determination of the species was determined as asteriscus.
\end{abstract}

Keywords: Common Carp, Age determination, Cyprinus carpio, Çoğun Dam Lake.

\footnotetext{
${ }^{1}$ Kırşehir Ahi Evran Üniversitesi, Fen Bilimleri Enstitüsü/Biyoloji Bölümü, Kırşehir, Türkiye, zaferarslan04@gmail.com

${ }^{2}$ Kırşehir Ahi Evran Üniversitesi, Çiçekdağı Meslek Yüksekokulu/Veterinerlik Bölümü, Kırşehir, Türkiye, rmznyzci@gmail.com
}

${ }^{1}$ https://orcid.org/0000-0003-1021-7740 ${ }^{2}$ https://orcid.org/0000-0003-2274-0707 


\section{Giriş}

Ülkemizde ekonomik olarak önemli bir tür olan sazan balıklarının (Cyprinus carpio Linnaeus,1758), sıcaklık toleransının yüksek olması, yetiştirme sırasında yakalanma ve çeşitli işlemlere dayanıklı olması, 5 ile 9 arasındaki pH aralığında yaşayabilmesi ve oksijen gereksiniminin az olması nedeniyle kültür balıkçılığı için uygun olduğu bilinmektedir (Pullin, 1986). Sazan balığ ülkemizde 7,223 ton/yıl üretim payı ile tatlı su balıkçılığı açısından önemli bir yere sahiptir (Anonim, 2015). Balık üretiminde yüksek verimin elde edilebilmesi için balıkların; büyüme oranları, yumurtlama dönemleri, yaşam süreleri, ölüm oranlarının tespit edilmesi ve verilerin güncellenmesi gerekmektedir. Bu bilgiler de ancak doğru yaş verileriyle elde edilebilir (Polat, 1986). Balıkçılık kaynaklarının yönetiminde kullanılan populasyon dinamiği çalışmalarında yaş verileri oldukça önemlidir (Ricker, 1975). Yaş tespiti geleneksel olarak kalsifiye yapılarda (pullar, omurlar, yüzgeç 1şınları, otolitler, operküller vs) mevsimlere bağlı olarak gerçekleşen büyüme bölgelerini göz önüne alarak yapılmaktadır (Chilton ve Beamish, 1982; Beamish ve McFarlane, 1983). Ancak balıkların yaşları tayin edilirken oldukça dikkat edilmelidir. Çünkü yaş tayininde yapılacak 1 yıllık bir hata dahi populasyon hakkında birçok verinin yanlış elde edilmesine neden olacaktır. Bu nedenle balıklarda yaş tayininin olabildiğince farklı kalsifiye oluşumlar kullanılarak yapılması ve her bir kalsifiye yapı bir okuyucu tarafından birden fazla kez ya da birçok okuyucu tarafindan okunarak okumalar arasındaki hatalar ve uyumlar değerlendirilerek güvenilir kalsifiye yapının tespit edilmesi gerekmektedir. Nitekim birçok balık türünde ve sazan balıklarında farklı habitatlarda güvenilir kalsifiye oluşum belirleme çalışmaları yapılmıştır (Gümüş ve ark., 2007; Yılmaz ve ark., 2007; Y1lmaz ve Polat, 2008; Y1lmaz ve ark., 2011; Hobbs ve ark., 2014; Yazıcı ve ark., 2014; Y1lmaz ve ark., 2015; Yazıcığlu ve ark., 2016; Khan ve ark., 2017; Klein ve ark., 2017; Long ve Nealis, 2017; Zhu ve ark., 2017.). Ancak Çoğun Baraj Gölü'nde herhangi bir araştırma mevcut değildir. Balıklarda yaş tayini yapılarının türden türe ve habitattan habitata değişebildiği bilinmektedir. Bu nedenle, bu araştırmada Çoğun Baraj Gölü'nden elde edilen Cyprinus carpio örneklerinde güvenilir kalsifiye oluşumu belirlemek ve tespit edilen güvenilir oluşumun diğer yapılarla kıyaslanması ile türün bu lokasyondaki güvenilir yaş tayini yapısını belirlemek amaçlanmıştır.

\section{Materyal ve Metot}

\subsection{Araştırma Alanı}

Kırşehir ili, merkeze bağlı Çoğun köyünde bulunan Çoğun Baraj Gölü 39³2’38.7" kuzey enlemi ve $34^{\circ} 11^{\prime} 83.22^{\prime \prime}$ doğu boylamı ile $39^{\circ} 34^{\prime} 11.33 .7^{\prime \prime}$ kuzey enlemi ve $34^{\circ} 09^{\prime} 26.5^{\prime \prime}$ doğu boylamı 
arasında uzanmaktadır (Köksaldı, 2020). Kırşehir'e 15 kilometre uzaklıkta bulunan Çoğun Baraj Gölü, kentin kuzeyinde, Çoğun köyünün kuzeybatısındadır. Araz Çayı'nın üzerinde kurulan baraj. 1970'li yılların ortasında taşkın koruma ve tarımsal alanların sulanması amacı ile hizmete açılmıştır. Temelden yüksekliği 43 metre olup 22 milyon metreküp su toplama kapasitesine sahiptir (Köksaldı, 2020). Çoğun Baraj Gölü’nün etrafında DSİ'nin yaptığı ağaçlandırma sahası dışında çevre düzenlemesi yapılmadığından ve tarım alanlarının çokluğundan dolayı göl çanağı erozyona açık bir konumdadır (Pektaş, 2001). Çoğun Baraj Gölü'nün balık faunasını 2 familyaya ait (Cyprinidae, Atherinidae) 3 tür oluşturmaktadır. Bunlar; Cyprinidae familyası üyesi Cyprinus carpio Linnaeus, 1758, Capoeta sieboldi Steindachner, 1864 ve Atherinidae familyası üyesi Atherina boyeri Risso, 1810 türleridir (Köksaldı, 2020).

\subsection{Avcılık ve Laboratuvar Süreçleri}

Balık örnekleri Haziran 2019-Şubat 2020 tarihleri arasında Çoğun Baraj Gölü’nün çeşitli bölgelerinden elde edilmiştir. Örneklemede 50x50, 55x55 mm göz açıklığına sahip fanyalı uzatma ağlar kullanılmıştır. Ağlar bir gün önceden göle serilmiş olup ertesi gün geri toplanmıştır. Avlanmalar sonucunda 120 adet sazan balığı elde edilmiştir. Yakalanan balıklar, içerisinde buz bulunan taşıma çantaları ile Kırşehir Ahi Evran Üniversitesi Hidrobiyoloji Araştırma Laboratuvarı'na getirilmiş, su ile yıkanarak, üzerlerindeki kirler ve mukus tabakası temizlenmiştir. Örneklerin total, çatal ve standart boyları $\pm 1 \mathrm{~mm}$ hassasiyetle balık ölçüm tahtasında ölçülmüş, ağırlıkları ise $\pm 0.01 \mathrm{~g}$ hassasiyetli hassas terazi ile tartılmıştır. Eşey tayini gonadların makroskobik incelenmesiyle yapılmıştır. Yaş tayini için pul, omur, asteriskus ve lapillus otolitler, operkül ve suboperkül yapıları alınmış ve yaş okumaya hazır hale getirilmiştir. Pul, omur ve otolitler Chugunova (1963)'nın, operkül ve suboperküller Astanin (1974)'nin önermiş olduğu yöntemle preparat haline getirilmiştir.

\subsection{Veri Analizleri}

Ön incelemeler neticesinde türün 6 kalsifiye yapısından (Pul, omur, asteriskus, lapillus, operkül ve suboperkül) da yaş tayini yapılabileceği kanısına varılmıştır. Yaş okumaları bir okuyucu tarafından, binoküler mikroskopta 10x büyütmede ve farklı zamanlarda 3 kez tekrarlanmıştır. Okumalar esnasında boy ve ağırlık verileri dikkate alınmamış olup sadece yakalanma tarihi ve gonad durumu göz önünde bulundurulmuştur. Örneklerin gerçek yıl sınıflarına yerleştirilmeleri Kuzey yarım kürede yaşayan balıklar için kabul edilen 1 Ocak tarihine göre yapılmıştır. C. carpio türünde tekrarlı yaş okumaları neticesinde elde edilen verilerden, yüzde uyum (YU), ortalama yüzde hata (OYH)ve değişim katsayısı (DK) gibi hesaplamalar yapılmıştır. 
Yüzde uyum, tekrarlı yaş okumaları arasındaki uyumun tespit edilmesinde kullanılan geleneksel bir yöntemdir. Bu yöntemle her bir kalsifiye oluşum için elde edilen tekrarlı okumalardaki benzerlik derecesi belirlenmekte ve yüzde olarak ifade edilmektedir. Bu çalışmada uyum sayısı tam yaş ve \pm 1 yaş uyumu olmak üzere kategorize edilmiştir. Her bir kategorideki örnek sayısı toplam örnek sayısına bölünerek yüzde (\%) cinsinden ifade edilmektedir.

Bir populasyondaki tüm örnekler için ayrı ayrı hesaplanan OYH'lerin ortalamaları alınmıştır. OYH hesabı için aşağıdaki denklem kullanılmıştır (Beamish ve Fournier, 1981).

$$
O Y H_{j}=100 \% \frac{1}{R} \sum_{i=1}^{R} \frac{\left|x_{i j}-x_{j}\right|}{x_{j}}
$$

Formülde; $\mathrm{OYHj}=\mathrm{j}$ balığı için ortalama yüzde hata, $\mathrm{Xij}=\mathrm{j}$ balığında i’inci yaş okuması, $\mathrm{Xj}=\mathrm{j}$ balığında ortalama yaş, $R=j$ balığı için yapılan tekrarlı okuma sayısını ifade etmektedir. Değişim katsayısı (DK) hesabında Chang (1982)’ın önerdiği ve aşağıda gösterilen denklem kullanılmıştır.

$$
D K_{j}=100 \% \frac{\sqrt{\sum_{i=1}^{R} \frac{\left(x_{i j}-x_{j}\right)^{2}}{R-1}}}{x_{j}}
$$

Formülde; $D K j=j$ balığı için değişim katsayısı, $X \mathrm{ij}=\mathrm{j}$ balığında i'inci yaş okuması, $X \mathrm{Xj}=\mathrm{j}$ balığ için ortalama yaş, $R=\mathrm{j}$ balığı için yapılan tekrar okuma sayısını ifade etmektedir.

Çoğun Baraj Gölü’nde yaşayan Cyprinus carpio bireylerinden elde edilen yaş verilerinden yukarıdaki hesaplamalar yapılmış olup yüksek uyum ve düşük ortalama yüzde hataya sahip olan kalsifiye yapı güvenilir yaş tayini yapısı olarak kabul edilmiştir. Güvenilir kalsifiye yapı ile diğer yapılar arasındaki uyuma da bakılarak güvenilir kalsifiye yapıya en yakın yaş veren yapı tespit edilmiştir.

\section{Bulgular ve Tartışma}

Çoğun Baraj Gölü’nde yaşayan Cyprinus carpio örnekleriden elde edilen pul (Şekil 1A), omur (Şekil 1B), asteriskus (Şekil 1C), lapillus (Şekil 1D), operkül (Şekil 1E) ve suboperküller (Şekil 1F) ön incelemeye tabi tutulmuş olup elde edilen tüm yapılarda yaş halkaları gözlenmiştir. 


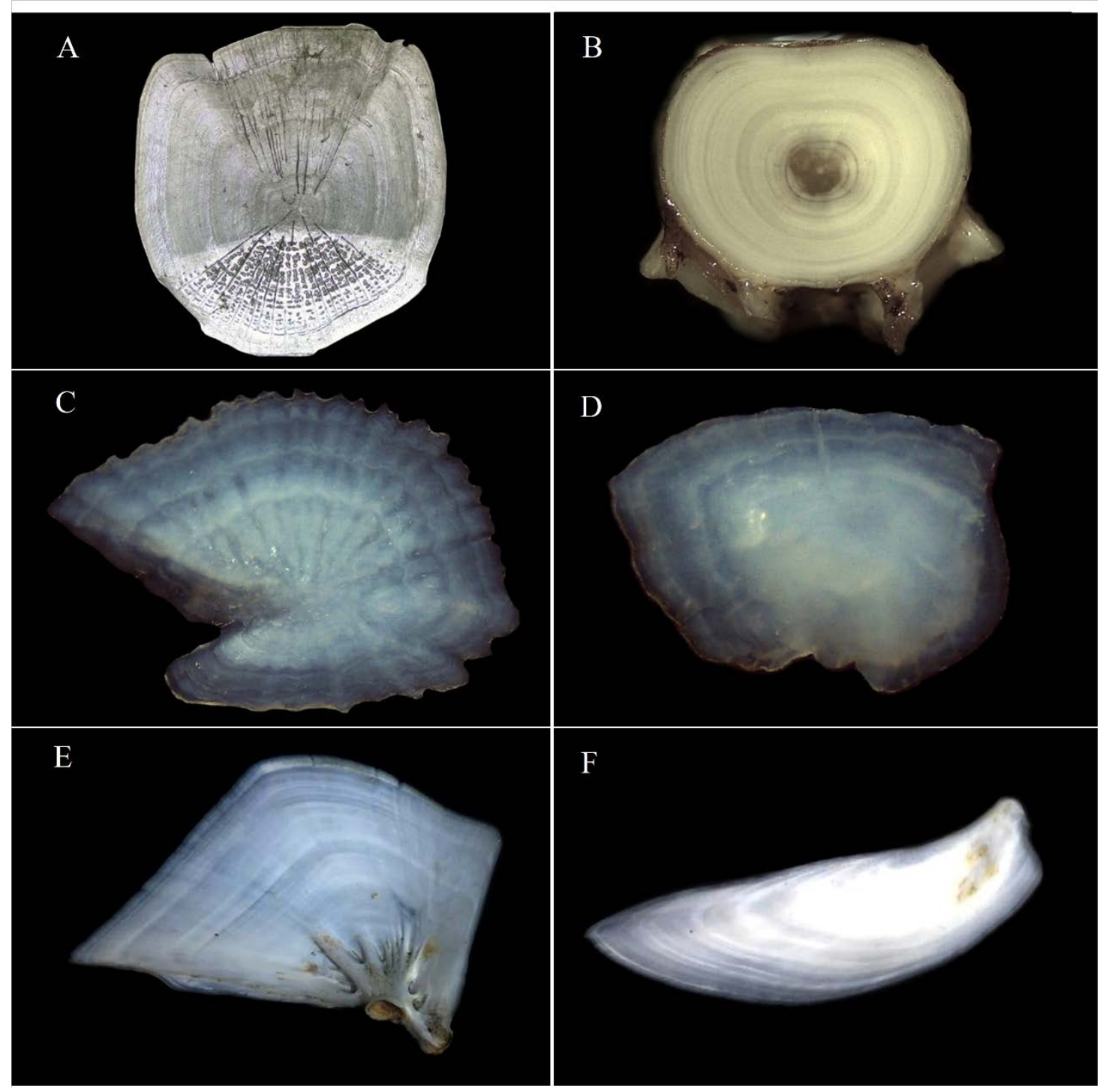

Şekil 1. Cyprinus carpio türünün kalsifiye yapıları (A: pul; B: omur; C: asteriskus; D: lapillus; E: operkül; F: suboperkül).

Tekrarlı yaş okumları sonucunda 3-6 arası yaşlar elde edilmiştir. Bütün yapılarda 4 yıl sınıfı oluşmuştur. Elde edilen yaş grupları ile her yaş grubundaki örnek sayıları ve yüzdeleri Tablo 1'de verilmiştir Yaş analizleri yapılabilen örneklerin tümü dikkate alındığında bütün yapılarda 5 yaş grubunun baskın olduğu belirlenmiştir (Tablo 1). 
Tablo 1. Örneklemde yaş gruplarına göre örnek sayıları ve yüzdeleri.

\begin{tabular}{|c|c|c|c|c|c|c|}
\hline \multirow{2}{*}{$\begin{array}{l}\text { Kalsifiye } \\
\text { Yapı }\end{array}$} & & \multirow[b]{2}{*}{3} & \multicolumn{3}{|c|}{ Yaş Grupları } & \multirow[t]{2}{*}{ Toplam } \\
\hline & & & 4 & 5 & 6 & \\
\hline \multirow{2}{*}{ Pul } & $\mathrm{N}$ & 1 & 34 & 69 & 16 & 120 \\
\hline & $\%$ & 0.8 & 28.3 & 57.5 & 13.4 & 100 \\
\hline \multirow{2}{*}{ Omur } & $\mathrm{N}$ & 1 & 43 & 67 & 9 & 120 \\
\hline & $\%$ & 0.8 & 35.8 & 55.8 & 7.6 & 100 \\
\hline \multirow{2}{*}{ Lapillus } & $\mathrm{N}$ & 3 & 24 & 66 & 20 & 113 \\
\hline & $\%$ & 2.7 & 21.2 & 58.5 & 17.7 & 100 \\
\hline \multirow{2}{*}{ Asteriskus } & $\mathrm{N}$ & 3 & 22 & 70 & 17 & 112 \\
\hline & $\%$ & 2.7 & 19.6 & 62.5 & 15.3 & 100 \\
\hline \multirow{2}{*}{ Operkül } & $\mathrm{N}$ & 2 & 29 & 75 & 14 & 120 \\
\hline & $\%$ & 1.7 & 24.2 & 62.5 & 11.8 & 100 \\
\hline \multirow{2}{*}{ Suboperkül } & $\mathrm{N}$ & 2 & 38 & 72 & 4 & 116 \\
\hline & $\%$ & 1.7 & 32.8 & 62.2 & 3.4 & 100 \\
\hline
\end{tabular}

Sazan balıklarından elde edilen altı kalsifiye yapının yüzde uyum değerleri Tablo 2'de verilmiştir. Tam yaş uyumunun en yüksek olduğu kalsifiye yapının asteriskus (\%76.8) olduğu tespit edilmiştir. Ayrıca \pm 1 yaş uyumunun tüm yapılarda yüksek olduğu görülmektedir.

Tablo 2. Kalsifiye yapılarda yüzde uyum değerleri.

\begin{tabular}{lcccc}
\hline $\begin{array}{c}\text { Kalsifiye } \\
\text { Yapı }\end{array}$ & $\begin{array}{c}\text { Toplam } \\
\text { Örnek } \\
\text { Sayısı }\end{array}$ & $\begin{array}{c}\text { Okunabilen } \\
\text { Örnek } \\
\text { Sayısı }\end{array}$ & $\begin{array}{c}\text { Tam } \\
\text { Yaş } \\
\text { Uyumu }\end{array}$ & $\begin{array}{c}\mathbf{\pm 1} \\
\text { Yaş } \\
\text { Uyumu }\end{array}$ \\
\hline Pul & 120 & 120 & 44.2 & 91.6 \\
Omur & 120 & 120 & 49.2 & 91.6 \\
Lapillus & 120 & 113 & 53.5 & 99.1 \\
Asteriskus & 120 & 112 & 76.8 & 97.3 \\
Operkül & 120 & 120 & 34.2 & 91.6 \\
Suboperkül & 120 & 116 & 31.0 & 93.1 \\
\hline
\end{tabular}

Güvenilir yapının tespit edilmesi için kullanılan diğer uyum kriterlerinden olan, ortalama yüzde hata $(\mathrm{OYH})$ ve değişim katsayısı (DK) değerleri Tablo 3’te verilmiştir.

Tablo 3. Kalsifiye yapılarda OYH ve DK değerleri.

\begin{tabular}{llll}
\hline $\begin{array}{l}\text { Kalsifiye } \\
\text { Yapı }\end{array}$ & $\begin{array}{l}\text { Örnek } \\
\text { Sayısı }\end{array}$ & $\begin{array}{l}\text { Ortalama Yüzde Hata } \\
\text { (OYH } \pm \text { Sh) }\end{array}$ & $\begin{array}{l}\text { Değişim Katsayısı } \\
\text { (DK } \pm \text { Sh) }\end{array}$ \\
\hline Pul & 120 & $6.80 \pm 0.61$ & $9.62 \pm 0.86$ \\
Omur & 120 & $6.63 \pm 0.67$ & $9.37 \pm 0.94$ \\
Lapillus & 113 & $6.53 \pm 0.55$ & $9.24 \pm 0.77$ \\
Asteriskus & 112 & $2.79 \pm 0.52$ & $3.94 \pm 0.73$ \\
Operkül & 120 & $8.24 \pm 0.61$ & $11.66 \pm 0.86$ \\
Suboperkül & 116 & $8.67 \pm 0.62$ & $12.25 \pm 0.87$ \\
\hline
\end{tabular}


Ortalama yüzde hata ve değişim katsayısı değerleri nisbeten asteriskusta daha düşük bulunmuştur. Pul, omur ve lapillus yapıları birbirine benzer değerlere sahip olup operkül ve suboperkül yapılarında diğer yapılara nazaran daha yüksek ortalama yüzde hata ve değişim katsayısı değerleri hesaplanmıştır.

Yaş analizleri sonucunda elde edilen yüzde uyum, ortalama yüzde hata ve değişim katsayısı verilerinin değerlendirilmesi ile en yüksek yüzde uyum, en düşük ortalama yüzde hata ve değişim katsayısının asteriskusta olduğu saptanmıştır. Diğer bir ifade ile asteriskus diğer yapılara nazaran daha uyumlu yaşlar sunmuştur. Bu sebeple Cyprinus carpio türünün Çoğun Baraj Gölü populasyonu için en güvenilir yapı asteriskustur.

Cyprinus carpio türünün Çoğun Baraj Gölü için güvenilir yaş tayini yapısı olarak belirlenen asteriskus ile diğer yapılardan elde edilen yaşların karşılaştırılması Şekil 2'de sunulmuştur.

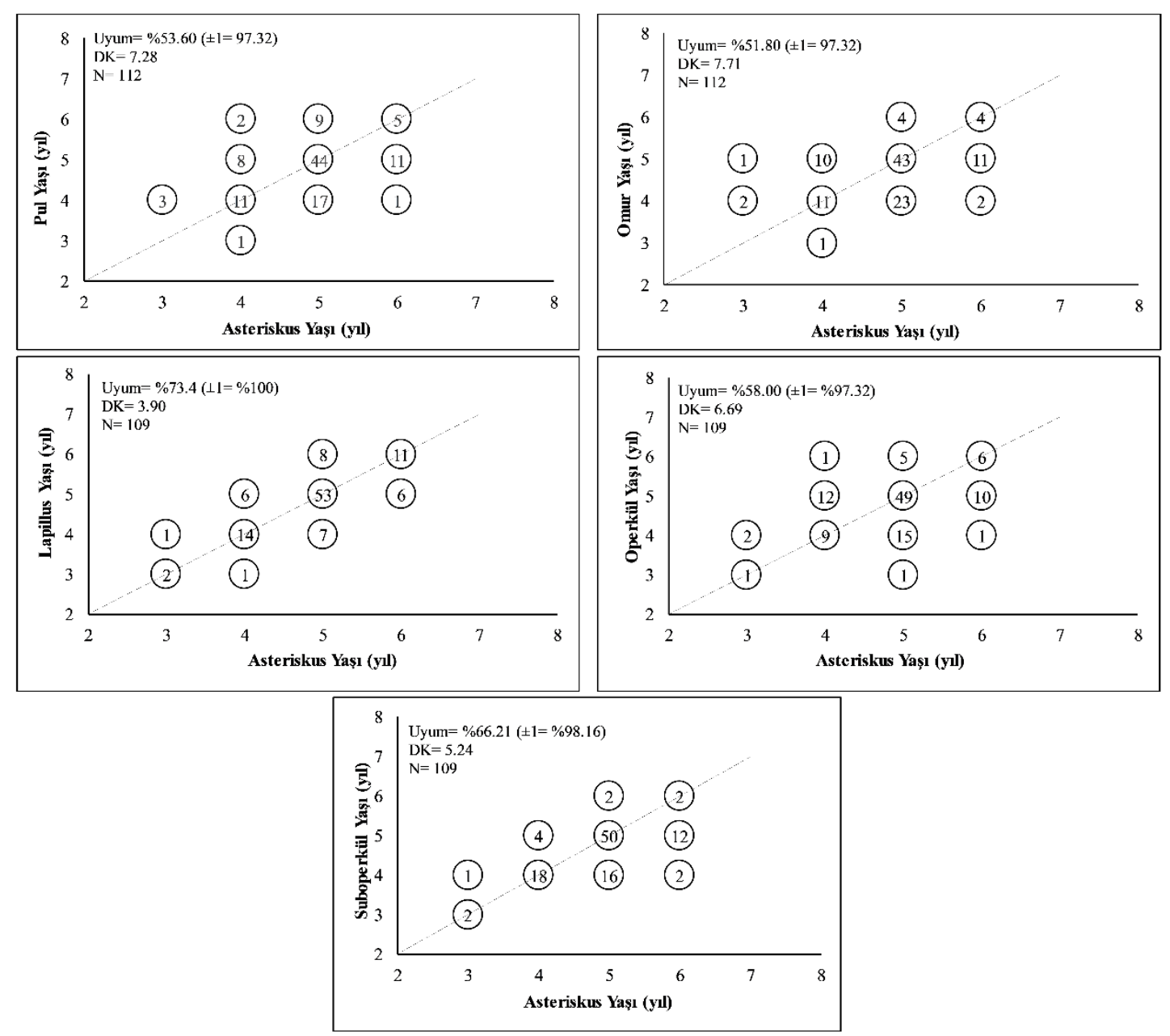

Şekil 2. Cyprinus carpio türünde güvenilir yapı ile diğer yapıların karşılaştırılması (DK: değişim katsayısı; $\mathrm{N}$ : örnek sayıs1). 
Güvenilir kalsifiye yapı ile diğer yapıların ikili karşılaştırmasında dikkate alınan YU ve DK değerlerine göre, asteriskus okumaları ile en uyumlu yaş verileri lapillustan elde edilmiştir. Ayrıca diğer yapılar ile \pm 1 yaş uyumlarına bakıldığında tüm yapıların güvenilir kalsifiye oluşuma yakın yaşlar verdiğini söylemek mümkündür (Şekil 2).

Bu çalışmada Çoğun Baraj Gölü’nde yaşayan ve sazan balığı olarak bilinen Cyprinus carpio türünde yaş tayini için ideal kalsifiye oluşum belirlenmiştir. Sazan balıklarında 6 farklı yapıdan yaş verileri alınabilmiştir. Bu yapıların her birinin ayrı ayrı değerlendirilmesi aşağıda ifade edilmiştir.

Pullar, kolay bir şekilde alınabilmesi ve balığın öldürülmesine gerek kalmaması açısından yaş tayininde her zaman en popüler kalsifiye yapı olarak değerlendirilmiştir (Vilizzi, 2018). Ancak bu çalışmada pullarda birtakım olumsuzluklar tespit edilmiştir. Pullarda absorbsiyonların görülmesi oldukça sık rastlanılan bir durum olmuştur. Bunun yanında çift halkaların gözlenmesi ve yalancı annulusların varlığı pulların yaş tayini açısından değerlendirilmesini güçleştirmektedir. Ayrıca preparasyon aşamasının zor ve dikkat isteyen bir iş olması pullardan yaş tayini yapılırken okuyucuların dikkat etmesi gereken bir durumdur. Nitekim pullarda yaş okuma esnasındaki benzer problemler farklı çalışmalarda da rapor edilmiştir (Vilizzi ve Walker, 1999; Yılmaz, 2006).

C. carpio örneklerinde omurlar özellikle boyutunun büyük olması dolayısı ile saklama ve okuma esnasında oldukça pratiktir. Buna karşın çift halka oluşumu, larval halka ve ilk yaş halkasının tespit edilmesinin zorluğu, temizleme esnasında üzerinde kalan doku parçalarının okuma güçlüğü oluşturması ve konkav yapısından ötürü yaş halkalarının oluşum takibinin yapılmasında zorlukların yaşanması yapının önemli dezavantajlarındandır. Bizim bulgularımızla benzer olarak Yılmaz (2006) yapmış olduğu çalışmada omurlarda çift halka karakterlerinin görülebildiğini ve bu durumun yüksek yaş verileri elde edilmesine neden olabileceğini belirtmiştir.

Sagittalar ince ve kırılgan yapıda olması sebebi ile preparasyon işlemleri sırasında yaş tayinine hazır hale getirilememiştir. Nitekim benzer bulguyu Yılmaz (2006) yaptığı araştırmada rapor etmiş ve alınabilen sagittalarda belirgin bir yaş halkası karakterinin gözlenemediğini bildirmiştir.

Lapilluslar örneklerin büyük bir çoğunluğundan rahatça elde edilmiştir. Lapilluslardan elde edilen yaşların daha güvenilir olduğu birçok balık türünde rapor edilmiştir. Ancak lapilluslarda özellikle merkez bölgesinde meydana gelen kalınlaşmalar yüzeyden yaş okuma konusunda olduğundan daha küçük yaşların tespit edilmesine neden olabilir. Nitekim Yazıcı (2018) Silurus glanis türünde yaptığı araştırmada yüzden okunan lapillusların kesit tekniğine göre daha küçük yaşlar verdiğini ve yapılacak yaş tayini çalışmalarında kesit tekniğinin kullanılması gerektiğini vurgulamıştır. Ayrıca C. Carpio türünde yapılan birçok araştırmada kırma-yakma ve kesit alma tekniği kullanılmış olup yaş tayini açısından oldukça faydalı veriler elde edilmiştir (Christensen, 1964; Aprahamian, 1987; Metin ve Kınacıgil, 2001; Aydın ve ark., 2009). 
Asteriskus örnekleri kırılgan bir yapıya sahip olduğu için balıklardan çıkarılırken kolayca kırılabilmektedir. Ayrıca zaman zaman merkez bölgesinde az da olsa kalınlaşmalar görülmesi yaş tayini açısından olumsuz bir durumdur. Ancak bu araştırmada asteriskuslardan oldukça düzenli yaş halkası oluşumları gözlemlenmiştir. Bazı numunelerin merkez bölgesindeki kalınlaşmalar zımparalama tekniği ile giderilmiş olup merkez halkalar ortaya çıkarılmıştır. Asteriskusta diğer tüm yapılara kıyasla çok daha düzenli yaş halkaları tespit edilmiştir. Benzer durum basılı literatürlerde de rapor edilmiştir (Vilizzi ve Walker, 1999; Yılmaz, 2006; Aydın, 2018).

$\mathrm{Bu}$ araştırmada operkül ve suboperkül örnekleri rahatlıkla temin edilmiş olup üzerindeki deri ve doku parçalarından arındırılmış ve yaş tayinine hazır hale getirilmiştir. Preparasyonunun kolay olması bu yapıları yaş belirleme açısından cazip kılsa da düzenli halka karakteri olmayışı, merkez bölgesindeki halkaların ayırt edilmesinin güçlüğü, uç kısımlarından kolayca kırılabilmesi ve büyük örneklerde zaman zaman kalınlaşmaların gözükmesi bu yapının yaş tayininde değerlendirilmesini güçleştirmektedir. Özellikle operküllerde meydana gelen kırılmalar ve yaş halkalarının silik ve takibinin zor olduğu basılı literatürlerde de belirtilmiştir (Bhandri ve ark., 1993; Gümüş, 1998; Vilizzi ve Walker, 1999; Y1lmaz, 2006).

Çoğun Baraj Gölü sazan örneklerinden alınan yapılarının tümü yaş tayinine uygun bulunmuş olup bir okuyucu tarafından 3 tekrarlı yaş okumaları neticesinde ortalama yaş, yüzde uyum (YU), değişim katsayısı (DK) ve ortalama yüzde hata (OYH) verileri elde edilmiştir (Tablo 1-2).

Yaş tayininde güvenilir yapının belirlenmesinde dikkate alınan YU, OYH ve DK değerlerine bakıldığında; her üç kriterin de yaş tayini açısından en güvenilir sonuçların elde edileceği kalsifiye oluşumun asteriskus olduğunu göstermektedir (Tablo 2-3). Asteriskus örneklerinde \%76.8 tam yaş uyumu elde edilmiştir. Asteriskustan sonra en yüksek yüzde uyum ise lapillusta tespit edilmiştir (\%53.5). Diğer yapılarda ise nispeten birbirine yakın uyum değerleri elde edilmiş olup en düşük tam yaş uyumu suboperkülde belirlenmiştir (Tablo 2). OYH (2.79) ve DK (3.94) değerlerinin de yine en düşük asteriskusta tespit edilmesi bu yapıda diğerlerine göre daha az hata ile yaş tayini yapıldığını göstermektedir (Tablo 3). Nitekim OYH değerinin \%5.5'in altında olması o yapının yaş tayini için oldukça ideal bir yapı olduğunu göstermektedir (Campana, 2001). Sonuç olarak, bu çalışmada yaş tayini için değerlendirilen yapılardan asteriskus en güvenilir yapı olarak tespit edilmiştir. Asteriskustan sonra en güvenilir yapının lapillus olduğu da yine elde edilen verilere göre göze çarpmaktadır. Nitekim yapılardan elde edilen yaşların karşıllaştırılması (Şekil 2) da bu sonucu desteklemektedir.

Daha önce yapılan çalışmalarda türün yaş verilerinin genellikle puldan elde edildiği görülmektedir (Yerli, 1997; Alp ve Balık, 2000; Özyurt ve Avşar, 2001; Kırankaya ve Ekmekçi, 2004; Balık ve ark., 2006; Demirkalp, 2007; Apaydın-Yağcı ve ark., 2008a; Apaydın-Yağcı ve ark., 2008b; Mert ve ark., 2008; Sedaghat ve ark., 2013; Mert ve Bulut, 2014). Buna karşın omur (Bishai 
ve Labib, 1978; Temizer ve Şen, 2008; Y1lmaz ve Polat, 2008), operkül (Mccornnell, 1952; Rehder, 1959), dorsal yüzgeç 1şını (Jackson ve ark., 2007; Watkins ve ark., 2015; Yates ve ark., 2016) ve pektoral yüzgeç 1şınlarından (Phelps ve ark., 2007) yaş verisi elde edilmiş araştırmalar da mevcuttur. Brown ve ark. (2004) Avusturalya'da ve Coulter ve ark. (2008) Nebraska Sandhıll Gölleri'nde yaptıkları araştırmada sazan balıklarının yaşlarını tespit etmek amacı ile asterikusları kullanmışlardır. Winker ve ark. (2010) yapmış olduğu araştırmada 816 asteriskus örneği incelemiş, diğer kalsifiye yapılarla yaptığı kıyaslama sonucunda sazan balıklarının yaş tayininde kullanılmasını önermiştir. Aydın, (2018), Altınkaya Barajı ve Bafra Balık Gölleri'nden elde ettiği sazanlarda asteriskuslardan kesit tekniği uygulayarak yaş tayini yapmıştır. Bolat ve Yağc1, (2018) Eğirdir Gölü’nden örnekledikleri C. carpio bireylerinde yaş tayini için asteriskusu güvenilir bulduklarını rapor etmişlerdir. Bu çalışma mevcut literatürlerle kıyaslandığında yaş tayini yapısı açısından asteriskusun tespit edilmesi başka çalışmalarda da rapor edilmiştir. Ayrıca yaş tayininde otolitlerin en doğru yaşı verdiği düşünülmüştür (Pontual, 2002; Campana ve Thorrold, 2001). Yaş tayini yapısının türden türe, habitattan habitata hatta aynı habitatta farklı stoklarda dahi değişebileceği bilinmektedir (Yılmaz, 2006). Bu nedenle yaş tayini araştırmaları habitata özgü olup mevcut literatürlerle uyumunun metodolojik ve ekolojik açıdan mukayese edilmesinin daha sağlıklı olacağı düşünülmektedir.

\section{Sonuçlar ve Öneriler}

Sonuç olarak bu çalışmada yaş tayininde kullanılmak üzere alınan 6 farklı yapının değerlendirilmesi yapılmış ve güvenilir kalsifiye yapının asteriskus olduğu tespit edilmiştir. Ancak elde edilen veriler ve gözlemler neticesinde diğer yapıların da yaş belirlemeye nispeten uygun olduğu söylenebilir. $\mathrm{Bu}$ durumun yapılacak araştırmalarda dikkate alınmasının önemli olduğu düşünülmektedir.

\section{Teşekkür}

$\mathrm{Bu}$ araştırmaya verdikleri desteklerden dolayı Çoğun Baraj Gölü yerel balıkçılarına teşekkür ederiz.

\section{Kaynaklar}

Alp, A., ve Balı, S. (2000). Growth conditions and stock analysis of the carp (Cyprinus carpio Linnaeus 1758) population in Gölhisar Lake. Turk. J. Zool., 24, 291-304.
Anonim.
(2015).
Türkiye
2015
y1li
su ürünleri
raporu, https://www.zmo.org.tr/genel/bizden_detay.php?kod=27302\&tipi=38\&sube=0. 
Apaydın-Yağcı, M., Alp, A., Yeğen, V., Uysal, R., Yağcı, A., ve Ceylan, M. (2008a). The growth characteristics of carp (Cyprinus carpio L., 1758) population in Lake Iş1klı (Çivril-Denizli). Ege University Journal of Fisheries \& Aquatic Sciences, 25(4), 337-341.

Apaydın-Yağcı, M., Uysal, R., Yeğen, V., Çetinkaya, S., Cesur, M., Bostan, H., ve Yağcı, A. (2008b). The some biological features of carp population (Cyprinus carpio L., 1758) in Lake İznik (Bursa). Ege University Journal of Fisheries \& Aquatic Sciences, 25(1), 19-25

Aprahamian, M. W. (1987). Use of the burning technique for age determination in eels (Anguilla anguilla L.) derived from the stocking of elvers. Fisheries Research, 6, 93-96.

Astanin, L. P. (1974). Ob. Opredelenii Vozrasta Ryb po Kostyum. (Age Determination in Fish from Bones). Zoologicheskii Zhurnal, 26, 3.

Aydın, A. (2018). Sazan balığ (Cyprinus carpio L., 1758)'nın yaş tayininde otolit yönteminin kullanılması ve otolit morfometrisinin iki populasyon arasında karşılaştırmalı analizi, Yüksek lisans tezi, Ondokuz Mayıs Üniversitesi Fen Bilimleri Enstitüsü, Samsun.

Aydın, R., Pala, M., Yüksel, F., ve Şen, D. (2009). Aynalı sazan (Cyprinus carpio L., 1758) otolitlerinde kırmayakma yöntemiyle yaş tayini. Journal of FisheriesSciences. com, 3(1), 51.

Balık, İ., Çubuk, H., Özkök, R., ve Uysal, R. (2006) Some characteristics and size of carp (Cyprinus carpio L., 1758) population in the Lake Karamık (Afyonkarahisar/Turkey). Turkish Journal of Fisheries and Aquatic Sciences, 6, 117-122.

Beamish, R. J., ve Fournier, D. A. A. (1981). Method for comparing the precision of a set of age determinations. Canadian Journal of Fisheries and Aquatic Sciences, 38, 982-983.

Beamish, R. J., ve McFarlane, G. A. (1983). The forgetten requirement for age validation in fisheries biology. Trans. Amer. Fish. Soci., 112 (6), 735-743.

Bhandari, B. S., Johal, M. S., ve Tandon, K. K. (1993). Age and growth of Cyprinus carpio var. communis linnaeus from gobindsagar. Himachal Pradesh, India. Res. Bull. Panjab Univ., 43 (1-4), 151-167.

Bishai, H. M. ve Labib, W. D. (1978). Age and growth of Mirror Carp (Cyprinus carpio L.) at Serow Fish Farm. Bull. Inst. Ocean. Fish., 8,397-418.

Bolat, Y., ve Yağc1, A. (2018). A comparative study on age determination of carp (Cyprinus carpio Linnaeus, 1758) in Lake Eğirdir using otolith, vertebrae and scale counts. Journal of Agricultural Sciences, 24(2), 199-204.

Brown, P., Green, C., Sivakumaran, K. P., Stoessel, D., ve Giles, A. (2004). Validating otolith annuli for annual age determination of common carp. Trans. Amer. Fish. Soci., 133, 190-196.

Campana, S. E. (2001). Accuracy, precision and quality control in age determination, including a review of the use and abuse of age validation methods. Journal of Fish Biology, 59(2), 197-242.

Campana, S. E. ve Thorrold, S. R. (2001). Otoliths, increments, and elements: keys to a comprehensive understanding of fish populations?. Canadian Journal of Fisheries and Aquatic Sciences, 58(1), 30-38.

Chang, W. Y. B. A. (1982). Statistical method for evaluating the reproducibility of age determination. Canadian Journal of Fisheries and Aquatic Sciences, 39, 1208-1210.

Chilton, D. E., ve Beamish, R. J. (1982). Age Determination Methods for Fishes Studied by The Groundfish Program at The Pacific Biological Station. Department of Fisheries and Oceans.

Christensen, J. M. (1964). Burning of otoliths, a technique for age determination of soles and other fish. ICES Journal of Marine Science, 29(1), 73-81.

Chugunova, L. P. (1963). Age and Growth Studies in Fish, National Science Foundation, Washington.

Coulter, D. P., Jolley, J. C., Edwards, K. R., ve Willis, D. W. (2008). Common carp (Cyprinus carpio) population characteristics and recruitment in two nebraska sandhill lakes. Transactions of the Nebraska Academy of Sciences and Affiliated Societies, 31.

Demirkalp, F. Y. (2007). Some of the growth characteristics of carp (Cyprinus carpio L., 1758) in Çernek Lake (Samsun, Turkey). Hacettepe University Journal of Biology and Chemistry, 35(1), 57-65

Gümüş, A. (1998). Aynalı Sazan (Cyprinus carpio L.)' in kemiksi yapılarında birikim takibi metodu ile yaş doğrulaması, Doktora tezi, Ondokuz Mayıs Üniversitesi Fen Bilimleri Enstitüsü, Samsun.

Gümüş, A., Bostancı, D., Yılmaz, S., ve Polat, N. (2007). Age Determination of Scardinius erythrophthalmus (Cyprinidae) Inhabiting Bafra Fish Lakes (Samsun,Turkey) Based on Otolith Readings and Marginal Increment Analysis. Cybium, 31(1), 59-66.

Hobbs, J., Frisch, A. J., Mutz, S., ve Ford, B. M. (2014). Evaluating The Effectiveness of Teeth and Dorsal Fin Spines for Non-lethal Age Estimation of A Tropical Reef Fish, Coral Trout Plectropomus leopardus. Journal of Fish Biology, 84(2), 328-338.

Jackson, Z. J., Quist, M. C., Larscheid, J. G., Thelen, E. C., ve Hawkins, M. J. (2007). Precision of scales and dorsal spines for estimating age of common carp. Journal of Freshwater Ecology, 22(2), 231-239. 
Khan, A. M., Khan, S., ve Khan, S. (2017). Precision of Age Estimates in Striped Snakehead Channa striata (Bloch, 1793) from The Ganga River and Its Tributaries (Rivers Gomti and Yamuna). Journal of Applied Ichthyology, 33(2), 230-235.

Kırankaya, Ş. G., ve Ekmekçi, F. G. (2004). Gelingüllü Baraj Gölü’nde yaşayan aynalı sazan (Cyprinus carpio L., 1758) 'in büyüme özellikleri. Turk. J. Vet. Anim. Sci., 28, 1057-1064.

Klein, Z. B., Bonvechio, T. F., Bowen, B. R., ve Quist, M. C. (2017). Precision and Accuracy of Age Estimates Obtained from Anal Fin Spines, Dorsal Fin Spines, and Sagittal Otoliths for Known-Age Largemouth Bass. Southeastern Naturalist, 16(2), 225-234.

Köksaldı, E. (2020). Çoğun Baraj Gölü (Kırşehir- Türkiye) balık faunası üzerine bir araştırma, Yüksek lisans tezi, Kırşehir Ahi Evran Üniversitesi Fen Bilimleri Enstitüsü, Samsun.

Long, J. M., ve Nealis, A. A. (2017). Comparative Precision of Age Estimates from Two Southern Reservoir Populations of Paddlefish [Polyodon spathula (Walbaum, 1792)]. Journal of Applied Ichthyology, 33(4), 819-820.

McConnell, W. J. (1952). The opercular bone as an indicator of age and growth of the carp, Cyprinus carpio Linnaeus. Transactions of the American Fisheries Society, 81(1), 138-149.

Mert, R., Bulut, S., ve Solak, K. (2008). Some biological characteristics of Cyrinus carpio (L., 1758) inhibating in the Apa Dam Lake (Konya-Turkey). Afyon Kocatepe Üniversitesi Fen ve Mühendislik Bilimleri Dergisi, 8(2), 47-60.

Mert, R., ve Bulut, S. (2014). Some biological properties of carp (Cyprinus carpio L., 1758) introduced into Damsa Dam Lake, CappadCia Region, Turkey. Pakistan Journal of Zoology, 46(2), 337-346.

Metin, G., ve Kınacıgil, H. T. (2001). Otolitten yaş tayininde kesit alma tekniği. Ege Üniversitesi Su Ürünleri Dergisi, 18, 271-277.

Özyurt, C. E., ve Avşar, D. (2001). Seyhan Baraj Gölü sazan (Cyprinus carpio Linnaeus, 1758) 'ların bazı biyolojik özelliklerinin belirlenmesi. Ege Üniversitesi Su Ürünleri Dergisi, 18 (3-4), 333-342.

Pektaş, M. (2001). Çoğun Baraj Gölü (Kırş̧ehir) alg florası, Yüksek Lisans Tezi, Tokat Gazi Osman Paşa Üniversitesi Fen Bilimleri Enstitüsü, Tokat.

Phelps, Q. E., Edwards, K. R., ve Willis, D. W. (2007). Precision of five structures for estimating age of common carp. North American Journal of Fisheries Management, 27(1), 103-105.

Polat, N. (1986). Keban Baraj Gölü'ndeki bazı balıklarda yaş belirleme yöntemleri ile uzunluk-ağırlık iliskkileri, Doktora tezi, Fırat Üniversitesi Fen Bilimleri Enstitüsü, Elazı̆g.

Pontual, H. (2002). Chapter 7 Otolith Microchemistry. Manual of Fish Sclerochronology, In: Troadec, H., ve Wright, P. J. (eds), Ifremer-lRD coedition, France.

Pullin, R. S. V. (1986). Woldwide status of carp culture, Aquaculture of cyprinids. In: Billard, R., Marcel, J., INRA, Paris, 21-34.

Rehder, D. D. (1959). Some aspects of the life history of the carp, Cyprinus carpio, in the Des Moines River, Boone County, Iowa. Iowa St.J. Sci., 34,11-26.

Ricker, W. E. (1975). Computation and interpretation of biological statistics of fish populations. Bull. Fish. Res. Board. Can., Kanada.

Sedaghat, S., Hoseini, S. A., Larijani, M., ve Ranjbar, K. S. (2013). Age and growth of common carp (Cyprinus carpio Linnaeus, 1758) in Southern Caspian Sea, Iran. World Journal of Fish and Marine Sciences, 5(1), 71-73.

Temizer, A., ve Şen, D. (2008). Keban Baraj Gölü'nde yaşayan aynalı sazan (Cyprinus carpio L.,1758)’ da kemiksi yapılardan karşılaştırmalı yaş tayini. Fırat Üniversitesi Fen ve Mühendislik Bilimleri Dergisi, 20(1):57- 66.

Vilizzi, L., ve Walker, K. F. (1999). Age and growth of the common carp, Cyprinus carpio, in the River Murray, Australia: validation, consistency of age interpretation, and growth models. Environmental Biology of Fishes, 54, 77-106.

Vilizzi, L. (2018). Age determination in common carp Cyprinus carpio: history, relative utility of ageing structures, precision and accuracy. Reviews in Fish Biology and Fisheries, 28(3), 461-484.

Watkins, C. J., Klein, Z. B., Terrazas, M. M., ve Quist, M. C. (2015). Influence of sectioning location on age estimates from Common Carp dorsal Spines. North American Journal of Fisheries Management, 35(4), 690-697.

Winker, H., Weyl, O. L. F., Booth, A. J. ve Ellender, B. R. (2010). Validating and corroborating the deposition of two annual growth zones in asteriscus otoliths of common carp Cyprinus carpio from South Africa's largest impoundment. Journal of Fish Biology, 77(10), 2210-2228.

Yates, J. R., Watkins, C. J., ve Quist, M. C. (2016). Evaluation of hard structures used to estimate age of common carp. Northwest Science, 90(2), 195-205. 
Yazıcı, R., Yılmaz, S., Yazıcığlu, O., ve Polat, N. (2014). The determination of the most reliable ageing method for the rudd (Scardinius erythrophthalmus L., 1758) population in Lake Ladik, Samsun, Turkey. Ege J Fish Aqua Sci, 31(1), 27-33. doi: 10.12714/egejfas.2014.31.01.05

Yazıcı, R. (2018). Sıddıklı Küçükboğaz Baraj Gölü'ndeki Yayın balığı (Silurus glanis L., 1758)'nın biyolojik özellikleri, Doktora tezi, Kırşehir Ahi Evran Üniversitesi Fen Bilimleri Enstitüsü, Kırşehir.

Yazıcıŏlu, O., Polat, N., ve Yılmaz, S. (2016). Ladik Gölü (Samsun)'nde yaşayan turna balığı (Esox lucius L., 1758)'nda yaş tayini için farklı kemiksi yapıların değerlendirilmesi. Journal of Limnology and Freshwater Fisheries Research, 2(3), 165-171.

Yerli, S. V. (1997). An investigation on the growth criterias of Cyprinus carpio Linnaeus 1758 in Çıldır LakeArdahan. Turkish Journal of Zoology, 21, 91-99.

Yılmaz, S. (2006). Samsun ili tatlı sularında yaşayan bazı ekonomik balık populasyonlarında yaş belirleme, Doktora tezi, Ondokuz Mayıs Üniversitesi-Fen Bilimleri Enstitüsü, Samsun.

Y1lmaz, S., Y1lmaz, M., ve Polat N. (2007). Age Determination from Six Bony Structures of Chub (Leuciscus Cephalus L., 1758) Inhabiting Divanbaş1 Pond (Kavak, Samsun) (in Turkish with English abstract). Istanbul University Journal of Fisheries \& Aquatic Sciences, 23, 67-80.

Yılmaz, S., ve Polat, N. (2008). Cyprinus Carpio L., 1758 (Sazan)'nun yaş tayini için farklı kemiksi yapıların değerlendirilmesi. SDÜ Fen Edebiyat Fakültesi Fen Dergisi, 3(2),149-161.

Yılmaz, S., Suiçmez M., ve Şeherli T. (2011). Precision of Ages Determined from Four Bony Structures of Chondrostoma regium (Heckel, 1843) in Almus Dam Lake (Tokat, Turkey). The Black Sea Journal of Science, 2(1), 24-34.

Yılmaz, S., Yazıcıoğlu, O., Yazıcı, R., ve Polat, N. (2015). Age, growth and reproductive period of white bream, Blicca bjoerkna (L., 1758) in Lake Ladik, Turkey. Journal of Limnology and Freshwater Fisheries Research, 1(1), 9-18.

Zhu, X., Wastle, R., Leonard, D., Howland, K., Carmichael, T. J., ve Tallman, R. F. (2017). Comparison of Scales, Pectoral Fin Rays, and Otoliths for Estimating Age, Growth, and Mortality of Lake Whitefish, Coregonus clupeaformis, in Great Slave Lake. DFO Can. Sci. Advis. Sec. Res., Kanada. 